\title{
Roles of the Jumps in Foreign Exchange Markets: A comparative Analysis of Non-Parametric Jump Tests ${ }^{1}$
}

\author{
Serkan YEŞILYURT iD a Ümit EROL (iD $b$ \\ a Bahçeşehir University, İstanbul, Turkey. serkan.yesilyurt@eas.bau.edu.tr \\ b Bahçeşehir University, İstanbul, Turkey. umit.erol@eas.bau.edu.tr
}

\begin{tabular}{l}
\hline ARTICLE INFO \\
\hline Keywords: \\
Jump detection models \\
High-frequency data \\
Pre-averaging \\
Macroeconomic news \\
News analysis
\end{tabular}

Received 27 Junuary 2021 Revised 10 Noveber 2021 Accepted 20 November 2021

Article Classification: Research Article

\section{ABSTRACT}

Purpose - The purpose of this study was to examine the effects of macroeconomic releases on jumps in foreign exchange markets using Barndorff-Nielsen and Shephard (2006), and AitSahalia and Jacod (2009) non-parametric jump detection tests and excel based event study methods are used to explore this effect. As part of this aim, the following questions were asked: "What are the differences between jump detection methods?". "Do jumps have long-term memory?". "Which type of event has more effect on foreign exchange markets?. Do US-based news have more effects on any market?". "Do co-jumps provide valuable information for the market practitioner?" and "Do co-jumps provide the significant signals?".

Design/methodology/data - The U.S, the U.K, Switzerland, Germany, Japan, France, Italy and Spain are represented as developed markets, while Turkey is represented as a developing country in Eastern Europe. I conduct our analysis on the foreign exchange market. The research data begins on January 1, 2010, and ends on December 31, 2016, with seven years of available high-frequency data. The highfrequency exchange rate data, extracted from www.histdata.com and Bloomberg data vendors. Each quote is time-stamped to seconds with two decimals in Greenwich Mean Time to Eastern Standart Time (GMT), starting from 00.00 Eastern Time (ET) to 23:59 GMT. Therefore, there are 1440 1-Minute, 288 5minute, 96 15-minute, 48 30-minute, and 24 60-minute intervals during the 24-hour foreign exchange market.

Findings - This study shows that scheduled news related to employment, real economic activities, trade balance, GDP, and FOMC rate decisions significantly affect jumps and co-jumps. The detected jumps are related to economic fundamentals, but jumps are only a small proportion of the sample news data. Jump doesn't have a long-term memory. The effect is latent and disappears very quickly (mean reversion in the long term). There are also speeches and unscheduled news, but scheduled news is more influential because it is announced more frequently.

Discussion - This research focused on the event time in this paper. However, the post-event time also has an important effect on matching the jumps. The results of this study can be used by finance practitioners and researchers, especially for behavioral finance cases. I established the importance of jumps and their relations with the macroeconomic news announcements. Apart from this research, we can extend this study to wavelet base new non-parametric tests by decomposing data into different time cycles and detect the arrival time of the jumps.

\section{INTRODUCTION}

The dynamics of asset prices are characterized by unpredictable price movements. One reason for this random behavior is the efficient market hypothesis (EMH). EMH mainly states that past price history is reflected in current prices. It also states that all available information is embedded by the price movements of the markets. The economics and finance literature's central issue is to explore the determinants of asset prices and return distributions. This is an important question that is investigated extensively in the literature. Asset prices can be assumed to be characterized by a continuous process if markets are dominated by normal events and characterized by the Brownian motion process. This is a process which is called continuous-time stochastic process written in the form of the stochastic differential equation below;

\footnotetext{
1 This research is derived from the thesis, named "Identifying jumps and Co-Jumps in Foreign Exchange Markets: A Comperative Analysis of Non Parametric Jump Tests" which was accepted in the Social Sciences Institute of Bahçeşehir University in the 2018-2019 Academic Year. 


$$
\frac{d s_{t}}{s_{t}}=\mu d t+\sigma d W_{t}
$$

$S_{t}=$ current asset price,

$\mu=$ the drift/trend term which is constant,

$\sigma=$ annualized volatility - constant,

$W_{t}=$ Standart Wiener process (Merton, 1976)

This process doesn't allow any discontinuity or "jumps" in the price process.

However, traded asset prices are subject to sudden movements that cannot be described by a continuous process. Such events mostly generate significant discontinuities called "jumps" in data series (Lee \& Mykland, 2008). The jump may differ in terms of its sign (positive or negative), magnitude (large or small), and frequency (recurring or rare) (Zoi, 2017). It is formulated as below

$$
\frac{d S_{t}}{S_{t}}=\mu d t+\sigma d W_{t}+d \sum_{j=1}^{N_{t}}\left(Y_{j}-1\right)
$$

The additional variable $Y_{j}-1$ here represents a log-normal distribution of a random variable. The jump size, $N_{t}$ comes from the Poisson process ${ }^{1}$ with parameter $\lambda \mathrm{t}$, and it represents unexpected shocks in price processes $d$ is the last parameter used as a constant term.

The jump detection procedure starts by defining the jump-diffusion processes. The continuous jump-diffusion modeling process has a long history in the finance literature and dates back to Merton's preliminary study (1976). This phenomenon has been discussed since Merton's propaedeutic study. Several studies, including Andersen et al. (1998), Zhu (1999), Cont and Tankov (2004), Bollerslev, Law, and Tauchen (2008) have examined the jump-diffusion process. The importance of jumps is widely accepted in the finance literature. A partial list of research which is published includes tests specification Andersen et al. (1998), Aith-Sahalia (2009), Barndorff-Nielsen and Shephard (2004a, 2006), Lee and Mykland (2008) and Aith-Sahalia and Jacord (2009) as well as seminal empirical studies of Maheu and Mccurdy (2004), Andersen et al. (2007), Bollerslev et al. (2008), Corsi et al. (2010), and Palmes et al. (2013). These are the non-parametric jump detection tests, but all these tests tell us on which day the jump occurred. Andersen et al. (2012), Lee and Mykland (2012), El Quadghiri, and Uctum (2016) tests detect the occurrence of the jumps. The problem of the non-parametric jump detection test is the existence of microstructural noise in the data series. It disputes the quality of the detected jumps. Besides the noise, other important factors, such as the threshold levels, affect the jump detection processes. These levels cannot catch up with some important jumps in the market.

Jumps are generally associated with a sudden flow of new information, but there is no general understanding of which kind of market events can generate discontinuous price movements. Also, much effort has been spent on detecting the sudden changes (also called a structural break) in the time series data (see Basseville and Nikiforov (1993), Shiau (1986), Yin (1988), Zu (1999), and Wang (1995). The structural break analysis shows that they are generated by sudden changes in either drift or volatility (Wong, \& Li, 2001). Asset prices may jump up or down due to the impact of important macroeconomic news or events (Qiu \& Yandell, 1998).

The jump and co-jump detection tests have been applied to different asset groups, such as Forex Market (FX), Stock Market, Bond Market, Interest rate markets, and derivative markets. The most important research in this area has been done in the FX market. We applied jump detection tests to extract jumps and co-jumps (simultaneous jumps) from USD, EUR, and CROSS exchange rate pairs in this research. We then symbolize the discontinuities' dynamics and informally relate them to the U.S, the U.K, Switzerland, Germany, Japan, France, Italy, Spain, Turkey, and Eurozone aggregate macroeconomic news releases. How big and usual are jumps and co-jumps across FX pairs? Do Jumps perform independently? What causes jumps and co-jumps in forex markets? Does only financial news cause FX jump or other economic releases affect the jumps and cojumps? Our research alternately answers these questions.

${ }^{1}$ See Neftci, S., (2008), An Introduction To The Mathematics Of Financial Derivatives. 
This study is a fundamental attempt to empirically verify the response of prices to new information, which is instrumental in price determination and ascertains the microstructure of markets and the price discovery process. Several studies considered financial price series as a continuous-time diffusion process. Several empirical studies have investigated such processes whose goals were to ascertain the sudden and severe price changes leading to violation of Gaussian distributions. According to Balduzzi et al. (2001), this type of empirical evidence found in currency markets has critical implications for portfolio applications, hedging, and derivative securities pricing. Moreover, the macroeconomic news effects analysis is fundamental because they offer an opportunity to determine how asset prices are related to the wider economy. It may show the leading role of economic fundamentals in equity and bond markets' price formulation process. However, economic fundamentals may be insufficient to explain the exchange rate movements fully. Barndorff-Nielsen and Shephard (2004) refer to this problem as a news puzzle and notes that some of the directional impacts are very difficult to be related to specific fundamentals since they are more often likely to be associated with other fundamentals as well.

The paper proceeds as follows: Section 2 describes the current conceptual framework on high-frequency price dynamics, jump, co-jumps, and price dynamics with the macroeconomic. Section 3 describes the jump and cojump detection test techniques and their properties. Section 4 describes the empirical results and performance of the jump and co-jump detection models. Section 5 provides concluding comments

\section{CONCEPTUAL FRAMEWORK}

Owing to the enormous advance in data processing technology, high-frequency data becomes an important area of financial econometrics in the world. It increases the prediction power of the forecasting model so that many econometric methods use high-frequency financial data - the availability of high-frequency data made jump detection analysis possible since 1995. Thanks to the availability of high-frequency data, the nature of the analysis evolved from investigating daily data to that of highly frequent intraday data.

The literature on jumps mainly consists of researchers detecting jumps, but more needs to be done regarding the detection of co-jumps and macroeconomic release analysis in forex market returns. However, there have been many individual asset class-based studies carried out, especially with the widely-used non-parametric jump detection methods including tests developed by Barndorf-Nielsen and Sephard (2006) (Called BNS method), Andersen et al. (2012) (called ADS method), Ait-Sahalia and Jacord (2009) (called AJ method), LeeMykland (2008-2012) (called LM method), Andersen et al. (2007) (called ABD method), Jiang and Omen (2008) (called JO method), Corsi et al. (2010) (called CPR method). The first attempt of this study is to measure and compare the existing BNS and AJ jump detection methods' performances. In addition to detecting the jumps, the co-jumps are detected among eleven FX currency pairs, and we also discuss their relationship with macroeconomic releases.

The mathematical properties of jump detection models make them powerful tools for analyzing highfrequency data. So, I use 1-minute, 5-minute, 15-minute, 30- minute, and 60-minute frequency return data (mid-price calculated as the average of high and low prices) of eleven currency pairs in FX markets.

One of the most important problems in the jump detection process is determining the optimal sampling frequency. The theory requires high-frequency data to confirm structural continuity, whereas high-frequency intraday data leaves room for the market microstructure noise. Market microstructure noise can be explained as the deviation from the observed asset prices. The optimal frequency problem is solved by the graphical tool method, which is known as the volatility signature plot developed by Andersen et al. (2007). This method reveals the effect of sampling frequency on volatility by plotting sampling intervals on the horizontal axis and volatility on the vertical axis. The logic behind the plot is that the variance of a price process is independent of the frequency. When I observe a distortion on the variance (realized one) measure for a certain frequency, then it can be said that microstructure noise distorts the frequency. The optimal frequency level is founded as 5 and 15 minutes by using this method. I also tested the 30 and 60 minutes frequencies as an alternatives.

I implement on different frequencies and models mentioned above to determine if 5-minutes and 15-minutes frequencies are optimal frequency levels for all cross pairs. In the second part of the analysis, the ABD and AJ 


\section{S. Yeşilyurt - Ü. Erol 13/4 (2021) 3559-3572}

methods are implemented and tested the model power by changing the threshold levels ${ }^{2}$. The general acceptance is that when the data frequency level increases, the models detect a lower percentage of jumps. The second dimension of this study is to determine the co-jump while measuring the performance of the existing jump detection methods. Jumps simultaneously occur in different cross pairs. This is very important information that is used by risk managers and practitioners in financial markets. The other contribution of this study is that we use macroeconomic news from the United States, the United Kingdom, Switzerland, Germany, France, Italy, aggregate Eurozone, China, India, and even Turkey. The pool here is unique and never used before.

We try to determine which macroeconomic news has a significant effect on jumps and jump sizes. Many jump detection analyses run on developed markets, but few studies are dedicated to emerging markets. This study will be unique since it also includes emerging ones. The study aims to answer the following questions in the rest of the sections:

i. What are the differences between jump detection methods?

ii. Do jumps have long-term memory?

iii. Which type of event has more effect on foreign exchange markets?

iv. Does the US-based news have more effects on any market?

v. Can any practitioners make abnormal returns by forecasting the jumps?

vi. Do co-jumps provide valuable information for the market practitioner?

vii. Do risk managers use the jumps or co-jumps for hedging strategies?

viii. Do co-jumps provide significant signals?

\section{THE RESEARCH, METHOD}

Jumps detection tests were developed in the last decade. Bardorff-Nielsen and Shephard developed the first seminal study on jump detection non-parametric method. This method compares the two realized measures of volatility:

i. The power variation

ii. Quadratic variation

Then, different alternative jump detection tests are developed.

We can mainly divide the jump detection methods into two family groups. The first family group is the BNS family group:

All tests are constructed on bipower variation and alternative measure, which is robust to jump volatility.

BNS type jump detection methods are developed by Corsi, Pirino, and Ren'o (2010), Andersen, et al. (2012), and Lahaye et al. (2011).

The second family group of jump detection is Lee and Mykland (2008). In this family group:

"Jumps can be identified when a return exceeds a certain threshold determined according to instantaneous volatility (Zoi, 2017)".

Andersen et al.(2007), Bollerslev et al. (2013), and Zoi and Ferriani (2017) studies focusses on the Lee and Mykland jump detection methods, but they differ in their methodology about volatility and threshold levels. Besides these two families, there are other jump detection methods such as Jiang and Oomen (2008), which use the swap variation and the test of Aith-Sahalia and Jacod (2009), which is based on absolute return moments calculated at different sampling frequencies (that we use in our analysis).

${ }^{2}$ I tested the power of the models to detect the jumps. So I changed the models threshold levels. For example: Andersen et all. (2003) make an empirical investigation on Dow Jones 30 stocks and the simulation corrected that the MinRV and MedRV estimators possess excellent jump robustness. We changed the MinRV and MedRV and find the new metric and new threshold levels. Based on this level that is implemented for this study. 
There are no common results in jump detection tests. This fact is empirically shown in Schwert's (2011) study. He used different identification methods and can generally get different conclusions on jump results. We also empirically tested the different family group jump detection tests and utilized the same results parallel to current literature.

\subsection{The BNS jump detection method}

Though their power and size in finite samples can be negatively affected by violent volatility shocks, these jump detection models are very flexible and consistent in the presence of volatility jumps (Zoi, 2017). The test statistic is not so complicated and uses some volatility metrics to compute the test statistics: It starts with the Realized variance metric:

$$
R V_{t}=\sum_{i=1}^{M} r_{t, i}^{2}
$$

In Andersen et al. (2010) study $R V_{t}$ metric converges to the quadratic variation. $(\mathrm{MM} \rightarrow \infty)$

$$
p \lim _{M \rightarrow \infty} R V_{t}=Q V_{t}=\int_{t-1}^{t} \sigma_{s}^{2} d s+\int_{t-}^{t} J_{s}^{2} d N_{s}
$$

If there is no jump in the time series data the $Q V_{t}$ corresponds the integrated variance $\left(I V_{t}\right)$.

$$
I V_{t}=\int_{t-1}^{t} \sigma_{s}^{2} d s
$$

To split the contribution of the continuous price variation from the contribution of the jump part, BarndroffNielsen and Shephard introduces the bipower variation, which is written as;

$$
B P V_{t} \equiv \mu_{1}^{-2}\left(\frac{M}{M-1}\right) \sum_{i=2}^{M}\left|r_{t, i-1}\right|\left|r_{t, i}\right|
$$

If there is a jump, the joint distribution of $B V_{t}$ and $I V_{t}$ normally distributed, is written as;

$$
\sqrt{M}\left(\begin{array}{ccc}
R V_{t} \rightarrow & I V \\
B V_{t, M} \rightarrow & I V
\end{array}\right) \vec{D} \rightarrow\left(0,\left[\begin{array}{cc}
2 & 2 \\
2 & 2,62
\end{array}\right] I Q_{t}\right)
$$

The integrated quarticity $\left(I Q_{t}\right)=\int_{t-1}^{t} \sigma_{s}^{4} d s$.

Besides those statistical computations, BNS is recommended as alternative statistics, which is a common and robust one;

$$
R J_{t}=\frac{R V_{t}-\widehat{I V}_{t}}{R V_{t}}
$$

$\widehat{I V}_{t}$ shows the jump robust measure of the $I V_{t}$.

I use this method with some modifications:

i. I first remove the zero intraday returns as recommended by Touchen and Zhou (2011). Zero return day increases the noise in the data.

ii. I use the mid-price, which is calculated (intraday high price + low price/2).

iii. I use the Holm-Bonferroni correction method, which is only proved to work if the p values are independent, although simulations have indicated that it works in correlated cases as well. Hence the Holm method is the default.

\subsection{Aith-Sahalia and Jacord jump detection methods}

Their test is constructed based on the power variation sampled at different frequencies. It examines the presence of jumps in the high-frequency data series.

The logic behind this method is to compare the multipower variation of equispaced returns computed at a fast time scale $h, r_{t, i}(i=1, \ldots \ldots, N)$ and it is computed at the slower time scale 


$$
\begin{aligned}
& \text { S. Yeşilyurt - Ü. Erol 13/4 (2021) 3559-3572 } \\
& \qquad k h, y_{t, i}\left(i=1 \ldots \ldots, \frac{N}{k}\right) .
\end{aligned}
$$

In their study, they realized that the limit (for $\mathrm{N} \rightarrow \infty$ ) of the realized power variation is invariant for different sampling group, and also their ratio is 1 in any case of jumps and $k^{p / 2}-1$ if no jumps. Hence, the Aith-Sahalia and Jacord test (henceforth is called as AJ test) detects the jumps using the ratio of realized power variation sampled from the two scales. This represents the null hypothesis if no jumps.

In $\mathrm{AJ}$ test functions return three results:

i. Z-test value: which is the threshold level to detect the jumps,

ii. Critical value: is used the defined whether there is a jump or not under the level of $95 \%$ and,

iii. P-value: the significance of the detected jumps.

Imagine that we have $\mathrm{N}$ equispaced returns in period $T . t_{t, i}$ depicts the return process of the pricing process (with $i=1, \ldots \ldots, N$ ) in period $T$.

There is also $N / k$ equispaced returns in period $T$. Let $y_{t, i}$ be a return (with $i=1, \ldots \ldots, N / k$ ) in period $T$.

Based on the above restriction, the $\mathrm{AJ}$ jump detection test is performed as;

$$
\text { AJ Test } t_{t, N}=\frac{S_{t}(p i k, h)-k^{\frac{p}{2}-1}}{\sqrt{V_{t, N}}}
$$

I also use this method with some modifications:

i. I first remove the zero intraday returns as recommended by Rognlie (2010). Zero return day increases the noise in the data.

ii. I use the mid-price, which is calculated (intraday high price + low price/2).

iii. I use the Holm-Bonferroni correction method only if the $\mathrm{p}$ values are independent, although simulations have indicated that it works in correlated cases as well. Hence the Holm method is the default

\subsection{Jumps and macroeconomic news: Event study analysis}

I chose the implement the Dewachter et al. (2014) event study approach with some modifications to realize the effects of macroeconomic news on jumps. I assume that news announcements cause jumps rather than jumps cause macroeconomic news. This is the preliminary assumption of this event study approach. I collected the news from the Bloomberg ECO's page with their significance level. Then I ranked all news according to its relevance level. I use the news whose relevance level is over 50 (Bloomberg's relevance ranking system from 0 to 100). To see how the news announcement (the actualized news) influences jumps, I analyze the jump dynamics at the time of the event. I don't use the event and pre-event study windows. This is measured by Dewachter et al. (2014) event study method but I don't use it in my study here. I used excel to find out the news effect on jumps.

First, I construct a conditional probability equation:

$$
P(\text { jumplevent })=\frac{\text { number of event match the jumps }}{\text { total number of events }}
$$

I also construct the alternative probability equation, which is an unconditional probability equation:

Then I set up a null hypothesis:

$$
P(\text { jumplevent })=\frac{\text { jumps occuers in the sub sample }}{\text { total number of the observation }}
$$

$$
\begin{aligned}
& H_{0}=P(\text { jump } \mid \text { event })=\text { jump } \\
& H_{1}=P(\text { jump } \mid \text { event }) \neq \text { jump }
\end{aligned}
$$

$H_{0}$ implies that a jump caused by an event is identical to $H_{1} \mathrm{~A}$ jump occurs without any event.

\section{FINDINGS}

Foreign exchange rate and macroeconomic news data are sourced from Bloomberg and histodata.com from January 1, 2010, to December 31, 2016. The jump detection methods were based on the Barbdorff-Nielsen and Diebold (BNS) and Aith-Sahalia and Jacord (AJ) jump detection tests. I also use the event study model, which matches the jumps with the macroeconomic news announcements in excel. Lastly, I interpret how news announcements affect jumps in the exchange rate return series. 


\section{S. Yeşilyurt - Ü. Erol 13/4 (2021) 3559-3572}

Table 1. provides a brief overview of eleven foreign exchange rate's return significant jump days for different frequencies based on z-score and p-values. It can be said that the jump sizes have become larger when the frequency increases from 1-minute to 30-minutes. This shows that the market volatility increases with the increasing frequency.

Table 1: Significant Jump days

\begin{tabular}{|c|c|c|c|c|c|c|c|c|c|c|c|}
\hline \multicolumn{3}{|c|}{1 Minute } & \multicolumn{3}{|c|}{5 Minutes } & \multicolumn{3}{|c|}{15 Minutes } & \multicolumn{3}{|c|}{30 Minutes } \\
\hline & b_ztest & b_pvalue & Date & b_ztest & p_pvalue & Date & b_ztest & b_pvalue & Date & b_ztest & p_pvalue \\
\hline $5 / 3 / 2010$ & 8.6828 & $3.9 \mathrm{E}-18$ & $11 / 19 / 2015$ & 21.857 & 0 & & 43.0589 & 0 & $4 / 22 / 2016$ & 43.0589 & 0 \\
\hline $7 / 30 / 2013$ & 7.72504 & $1.1 \mathrm{E}-14$ & & 22.552 & 0 & $3 / 20 / 2015$ & 21.7723 & $4.3 \mathrm{E}-105$ & $2 / 5 / 2014$ & 21.7723 & $4.3 \mathrm{E}-105$ \\
\hline $12 / 5 / 2011$ & 5.37245 & $7.8 \mathrm{E}-08$ & $3 / 20 / 2015$ & 21.549 & $3 \mathrm{E}-306$ & & 18.442 & $6.04 \mathrm{E}-76$ & $12 / 22 / 2016$ & 18.442 & $6.04 \mathrm{E}-76$ \\
\hline $5 / 2 / 2012$ & 4.85348 & $1.2 \mathrm{E}-06$ & $6 / 6 / 2011$ & 19.611 & $1.2 \mathrm{E}-85$ & $5 / 27 / 2015$ & 13.5899 & $4.6 \mathrm{E}-42$ & $3 / 28 / 2014$ & 13.5899 & $4.6 \mathrm{E}-42$ \\
\hline $4 / 20 / 2016$ & 4.10226 & $4.1 \mathrm{E}-05$ & $10 / 3 / 2013$ & 13.882 & $8.1 \mathrm{E}-44$ & $12 / 10 / 2012$ & 10.6902 & $1.13 \mathrm{E}-26$ & $6 / 4 / 2012$ & 10.6902 & $1.13 \mathrm{E}-26$ \\
\hline $12 / 16 / 2011$ & 3.99435 & $6.5 \mathrm{E}-05$ & & 13.197 & $9.1 \mathrm{E}-40$ & & 10.6856 & $1.19 \mathrm{E}-26$ & $7 / 22 / 2016$ & 10.6856 & $1.19 \mathrm{E}-26$ \\
\hline \multirow[t]{2}{*}{$3 / 29 / 2016$} & -3.7334 & 0.00019 & $12 / 30 / 2013$ & 12.515 & $6.2 \mathrm{E}-36$ & $8 / 5 / 2013$ & 8.67462 & $4.15 \mathrm{E}-18$ & $11 / 30 / 2012$ & 8.67462 & $4.15 \mathrm{E}-18$ \\
\hline & 3.61966 & 0.00029 & $8 / 5 / 2013$ & 12.059 & $1.7 \mathrm{E}-33$ & & 4873 & $3.68 \mathrm{E}-16$ & $9 / 1 / 2015$ & 8.14873 & $3.68 \mathrm{E}-16$ \\
\hline $9 / 7 / 2015$ & -3.6176 & 0.0003 & $1 / 6 / 2016$ & 11.129 & $9.1 \mathrm{E}-29$ & $10 / 3 / 2013$ & 527 & $2.1 \mathrm{E}-15$ & 013 & 7.93527 & $2.1 \mathrm{E}-15$ \\
\hline \multirow[t]{2}{*}{$2 / 24 / 2015$} & 3.51839 & 0.00043 & & 10.966 & $5.5 \mathrm{E}-28$ & $12 / 30 / 2013$ & 7.70796 & $1.28 \mathrm{E}-14$ & $3 / 29 / 2013$ & 7.70796 & $1.28 \mathrm{E}-14$ \\
\hline & 3.45019 & 0.00056 & $5 / 3 / 2016$ & 10.735 & $7 \mathrm{E}-27$ & $3 / 22 / 2012$ & 7.54789 & $4.42 \mathrm{E}-14$ & $11 / 18$ & 7.54789 & $4.42 \mathrm{E}-14$ \\
\hline $7 / 23 / 2014$ & -3.4052 & 0.00066 & $3 / 11 / 2013$ & 9.0002 & $2.3 \mathrm{E}-19$ & $1 / 5 / 2016$ & 7.29002 & $3.1 \mathrm{E}-13$ & 014 & 7.29002 & $3.1 \mathrm{E}-13$ \\
\hline $10 / 9 / 2014$ & 3.22995 & 0.00124 & & 8.8444 & $9.2 \mathrm{E}-19$ & $10 / 25 / 2011$ & 7.15092 & $8.62 \mathrm{E}-13$ & $7 / 27 / 2011$ & 7.15092 & $8.62 \mathrm{E}-13$ \\
\hline $6 / 3 / 2010$ & 3.18998 & 0.00142 & $1 / 5 / 2016$ & 8.6356 & $5.8 \mathrm{E}-18$ & $11 / 5 / 2015$ & 7.02271 & $2.18 \mathrm{E}-12$ & $7 / 7 / 2014$ & 7.02271 & $2.18 \mathrm{E}-12$ \\
\hline $4 / 1 / 2015$ & -3.1398 & 0.00169 & $12 / 5 / 2013$ & 8.5095 & $1.7 \mathrm{E}-17$ & & 6.7613 & $1.37 \mathrm{E}-11$ & $8 / 13 / 2015$ & 6.7613 & $1.37 \mathrm{E}-11$ \\
\hline \multirow[t]{2}{*}{$7 / 26 / 2010$} & -3.1133 & 0.00185 & $9 / 28 / 2016$ & 8.2505 & $1.6 \mathrm{E}-16$ & $3 / 22 / 2016$ & 866 & $1.79 \mathrm{E}-10$ & $10 / 2$ & 6.37866 & $1.79 \mathrm{E}-10$ \\
\hline & -3.0844 & 0.00204 & $4 / 15 / 2013$ & 7.5292 & $5.1 \mathrm{E}-14$ & $5 / 8 / 2014$ & 6.28087 & $3.37 \mathrm{E}-10$ & $6 / 27 / 2013$ & 6.28087 & $3.37 \mathrm{E}-10$ \\
\hline $7 / 5 / 2011$ & -3.0476 & 0.00231 & & 7.3202 & $2.5 \mathrm{E}-13$ & $7 / 29 / 2014$ & 6.24836 & $4.15 \mathrm{E}-10$ & $8 / 23$ & 6.24836 & $4.15 \mathrm{E}-10$ \\
\hline $5 / 28 / 2015$ & -3.0441 & 0.00233 & & 7.2075 & $5.7 \mathrm{E}-13$ & & 5.98479 & $2.17 \mathrm{E}-09$ & 015 & 5.98479 & $2.17 \mathrm{E}-09$ \\
\hline $2 / 10 / 2011$ & -3.0408 & 0.00236 & & 7.1514 & $8.6 \mathrm{E}-13$ & & 5.91076 & $3.41 \mathrm{E}-09$ & $6 / 5 / 2015$ & 5.91076 & $3.41 \mathrm{E}-09$ \\
\hline \multirow[t]{2}{*}{$8 / 4 / 2010$} & -3.0004 & 0.0027 & $12 / 23 / 2011$ & 6.5477 & $5.8 \mathrm{E}-11$ & $3 / 11 / 2013$ & 5.77713 & 7.6E-09 & $8 / 9 / 2012$ & 5.77713 & 7.6E-09 \\
\hline & -2.9565 & 0.00311 & $9 / 17 / 2013$ & 6.3059 & $2.9 \mathrm{E}-10$ & $10 / 29 / 2015$ & 5.71529 & $1.1 \mathrm{E}-08$ & $7 / 1 / 2014$ & 5.71529 & $1.1 \mathrm{E}-08$ \\
\hline $11 / 6 / 2015$ & -2.9536 & 0.00314 & & 6.1043 & $1 \mathrm{E}-09$ & $11 / 2 / 2015$ & 1529 & $1.1 \mathrm{E}-08$ & $7 / 3 / 2014$ & 5.71529 & $1.1 \mathrm{E}-08$ \\
\hline $1 / 7 / 2011$ & 2.9522 & 0.00316 & $11 / 6 / 2013$ & 6.0574 & $1.4 \mathrm{E}-09$ & & 5.70534 & $1.16 \mathrm{E}-08$ & $1 / 15 / 2016$ & 5.70534 & $1.16 \mathrm{E}-08$ \\
\hline \multirow[t]{2}{*}{$5 / 5 / 2016$} & -2.9368 & 0.00332 & $12 / 13 / 2016$ & 6.0438 & $1.5 \mathrm{E}-09$ & 9/9/2015 & 5.62439 & $1.86 \mathrm{E}-08$ & $6 / 3 / 2014$ & 5.62439 & $1.86 \mathrm{E}-08$ \\
\hline & -2.9081 & 0.00364 & $7 / 22 / 2016$ & 5.9473 & 2.7E-09 & $10 / 26 / 2012$ & 5.57926 & $2.42 \mathrm{E}-08$ & $4 / 30 / 2012$ & 5.57926 & $2.42 \mathrm{E}-08$ \\
\hline $5 / 25 / 2010$ & -2.8984 & 0.00375 & & 5.6232 & $1.9 \mathrm{E}-08$ & & 5.53886 & $3.04 \mathrm{E}-08$ & $8 / 18 / 2016$ & 5.53886 & $3.04 \mathrm{E}-08$ \\
\hline $9 / 25 / 2012$ & -2.8677 & 0.00413 & 7/9/2013 & 5.5625 & $2.7 \mathrm{E}-08$ & $7 / 22 / 2015$ & 5.5197 & $3.4 \mathrm{E}-08$ & $5 / 7 / 2014$ & 5.5197 & $3.4 \mathrm{E}-08$ \\
\hline $12 / 30 / 2011$ & -2.8624 & 0.0042 & $4 / 12 / 2016$ & 5.5179 & $3.4 \mathrm{E}-08$ & & 5.41261 & $6.21 \mathrm{E}-08$ & $2 / 4 / 2016$ & 5.41261 & $6.21 \mathrm{E}-08$ \\
\hline $8 / 18 / 2011$ & -2.8236 & 0.00475 & $7 / 12 / 2012$ & 5.4657 & $4.6 \mathrm{E}-08$ & $2 / 23 / 2015$ & 5.33973 & $9.31 \mathrm{E}-08$ & $1 / 17 / 2014$ & 5.33973 & $9.31 \mathrm{E}-08$ \\
\hline \multirow[t]{2}{*}{$1 / 23 / 2013$} & -2.7876 & 0.00531 & $2 / 6 / 2014$ & 5.3471 & $8.9 \mathrm{E}-08$ & $10 / 19 / 2015$ & 5.29882 & $1.17 \mathrm{E}-07$ & $6 / 20 / 2014$ & 5.29882 & $1.17 \mathrm{E}-07$ \\
\hline & 2.77887 & 0.00545 & $4 / 17 / 2015$ & 5.3076 & $1.1 \mathrm{E}-07$ & & 5.22985 & $1.7 \mathrm{E}-07$ & $7 / 13 / 2015$ & 5.22985 & $1.7 \mathrm{E}-07$ \\
\hline
\end{tabular}

Source: Author's own calculation.

Annualized returns show the volatility between the exchange rate pairs. Among the exchange rate pairs, the GBP/JPY currency pair is the most volatile one with an annualized standard deviation of $22.30^{3}$. Looking at the whole sample size, ${ }^{4}$ only a small proportion of the returns are detected as jumps. The test compares 1minute, 5-minutes, 15-minutes, and 30-minutes and 60-minutes frequency returns with critical values and threshold levels of the jump tests. The threshold levels of BNS and AJ tests are different.

\footnotetext{
${ }^{3}$ It is the highest annualized returns observed in 5, 15 and 3 minutes frequency.

${ }^{4} 1$ minute data: 2,587.655, 5-minute data: 735,264, 5-minute data: 245,088, 30-minute data: 122,544 and 60minute data: 61,272
} 
S. Yeşilyurt - Ü. Erol 13/4 (2021) 3559-3572

Table 2: Statistical properties of Aith-Sahalia jumps detected from the test under the $95 \%$ significance level from 2010 to 2016 (GBPJPY)

\begin{tabular}{|c|c|c|c|c|c|}
\hline AJ-GBPJPY & $\begin{array}{l}1 \text { Minutes } \\
\text { frequency }\end{array}$ & $\begin{array}{c}\text { Mins } \\
\text { Frequency } \\
\end{array}$ & $\begin{array}{c}15 \text { Mins } \\
\text { Frequency }\end{array}$ & $\begin{array}{c}30 \text { mins } \\
\text { Frequency }\end{array}$ & $\begin{array}{c}60 \text { mins } \\
\text { Frequency }\end{array}$ \\
\hline $\begin{array}{l}\text { Number of } \\
\text { Observation }\end{array}$ & $2,587,655.00$ & 735,264 & 245,088 & 122,544 & 61,272 \\
\hline $\mathrm{E}($ labs(return) $\mid)$ & 0.0001 & 0.0002 & 0.0004 & 0.0005 & 0.0003 \\
\hline Annualized SD & 22.23 & 22.30 & 22.30 & 22.30 & 22.29 \\
\hline $\begin{array}{l}\text { Number of sample } \\
\text { days }\end{array}$ & 1822 & 1822 & 1822 & 1822 & 1822 \\
\hline Number of Jumps days & 1047 & 1011 & 953 & 943 & 969 \\
\hline $\mathrm{P}$ (jump day) (\%) & 57.46 & 55.49 & 52.31 & 51.76 & 53.18 \\
\hline $\begin{array}{l}\text { E (jumps l jump day) } \\
(\%)\end{array}$ & 1.49 & 1.32 & 1.33 & 1.32 & 1.40 \\
\hline Number of Jumps & 1565 & 1332 & 1269 & 1242 & 1354 \\
\hline P(jump) (\%) & 0.000605 & 0.001812 & 0.005178 & 0.010135 & 0.022098 \\
\hline $\mathrm{E}($ ljumpsize $\mid)$ & 3.4128 & 0.9564 & 0.8135 & 0.675 & 1.4644 \\
\hline \# jump $>0$ & 632 & 783 & 572 & 592 & 645 \\
\hline$P$ (jump $>0)(\%)$ & 0.0244 & 0.1065 & 0.2334 & 0.4831 & 0.2119 \\
\hline $\mathrm{SD}($ jumpsize $\mid$ jump $>0)$ & 0.0753 & 0.0025 & 0.0043 & 0.0018 & 0.8857 \\
\hline$\#$ jump $<0$ & 933 & 549 & 697 & 650 & 709 \\
\hline $\begin{array}{l}P(\text { jump }<0)(\%) / P \\
\text { (jump }>0)(\%)\end{array}$ & 0.0361 & 0.0746 & 0.2844 & 0.5304 & 114.1707 \\
\hline $\mathrm{SD}($ jumpsize $\mid$ jump $<0)$ & 0.0013 & 0.0003 & 0.0002 & 0.0002 & 0.0002 \\
\hline$\%$ of negative jump & 59.62 & 41.22 & 54.93 & 52.33 & 52.36 \\
\hline SD & 1.24 & 1.35 & 1.40 & 1.42 & 1.36 \\
\hline
\end{tabular}

Source: Author's own calculation.

Based on the threshold level, the number of detected jumps changes over time. Table. 3 summarizes the frequency of the jumps between currency pairs. The number of detected jumps ranges from 986 in the EUR/JPY market to 1565 in the GBP/JPY market. Lahaye et al. (2011) indicate that foreign exchange rate markets have more jumps than the other markets such as stock and bond markets because FX market is theoretically has 24 hours trading intervals in a day. 
Table 3: Frequency of Jump days

\begin{tabular}{|c|c|c|c|c|c|c|}
\hline & 1-min & 5-min & 15-min & 30-min & 60-min & Currency \\
\hline AJ/n of Jump Days & 1433 & 1209 & 1257 & 1258 & 1289 & GBPCHF \\
\hline BNS-S / n of Jump Days & 1136 & 1330 & 1350 & 1258 & 1336 & GBPCHF \\
\hline $\mathrm{AJ} / \mathrm{n}$ of Jump Days & 1198 & 1301 & 1216 & 1254 & 1242 & GBPCHF \\
\hline BNS-S / n of Jump Days & 1198 & 1301 & 1216 & 1254 & 1216 & GBPCHF \\
\hline AJ/n of Jump Days & 1565 & 1332 & 1269 & 1242 & 1354 & GBPJPY \\
\hline BNS-S / n of Jump Days & 1565 & 1332 & 1269 & 1242 & 1236 & GBPJPY \\
\hline $\mathrm{AJ} / \mathrm{n}$ of Jump Days & 1155 & 1358 & 1277 & 1302 & 1273 & USDCHF \\
\hline BNS-S / n of Jump Days & 1155 & 1358 & 1277 & 1302 & 1429 & USDCHF \\
\hline AJ/n of Jump Days & 1253 & 1158 & 1001 & 1332 & 1193 & USDJPY \\
\hline BNS-S / n of Jump Days & 1168 & 1413 & 1057 & 1332 & 1241 & USDJPY \\
\hline $\mathrm{AJ} / \mathrm{n}$ of Jump Days & 1458 & 1383 & 1263 & 1358 & 1356 & USDTRY \\
\hline BNS-S / n of Jump Days & 1450 & 1466 & 1258 & 1263 & 1368 & USDTRY \\
\hline $\mathrm{AJ} / \mathrm{n}$ of Jump Days & 1477 & 1355 & 1204 & 1254 & 1323 & EURCHF \\
\hline BNS-S / n of Jump Days & 1117 & 1355 & 1204 & 1301 & 1244 & EURCHF \\
\hline $\mathrm{AJ} / \mathrm{n}$ of Jump Days & 1260 & 1143 & 1216 & 1307 & 1158 & EURGBP \\
\hline BNS-S / n of Jump Days & 1381 & 1326 & 1233 & 1252 & 1298 & EURGBP \\
\hline $\mathrm{AJ} / \mathrm{n}$ of Jump Days & 1257 & 1254 & 1103 & 986 & 1121 & EURJPY \\
\hline BNS-S / n of Jump Days & 1229 & 1415 & 1129 & 1173 & 1260 & EURJPY \\
\hline $\mathrm{AJ} / \mathrm{n}$ of Jump Days & 1332 & 1301 & 1258 & 1254 & 1286 & EURTRY \\
\hline BNS-S / n of Jump Days & 1258 & 1355 & 1452 & 1028 & 1219 & EURTRY \\
\hline $\mathrm{AJ} / \mathrm{n}$ of Jump Days & 1242 & 1332 & 1301 & 1242 & 1279 & EURUSD \\
\hline BNS-S / n of Jump Days & 1433 & 1216 & 1258 & 1433 & 1336 & EURUSD \\
\hline
\end{tabular}

Source: Author's own calculation.

Looking at the whole sample, only a small proportion of the returns are detected as jumps. The number of observation for frequencies are; 2,587.655 for 1-minute, 735,264 for 5-minutes, 245,088 for 15-minutes 122,544 for 30-minutes, and 61,272 for 60-minutes intervals. However, the largest jump day is observed as 1,565 days of GBP/JPY, but the whole observation percentage is only $0,0006 \%$. The size of the jumps is dependent on the critical values and significance levels. Based on the chosen methods, the size of the jump is changing. The labor market news plays a key role in that volatility fluctuation. El Ouadghiri and Uctum's (2016) study supports this finding. They underlined that the most influential scheduled macroeconomic news is globally related to the US job markets, public debt, GDP, and rescue plans (especially Obama's rescue plan). Moreover, during a similar study that was concerned with the exchange rates of euro-dollar, the researchers ascertained that verbal communications always results in large kind of jumps for nearly an hour after news announcements, an abnormal variation which the authors might have noted as a result of European official's interventions as opposed to the United States of American authorities.

The number of jump days is accounting for $48 \%$ to $68 \%$ fluctuation between currency pairs. The highest one is realized in USD/JPY in 5-min returns, and the lowest one is utilized in EUR/JPY in 1-minute. To analyze whether there is an asymmetry between positive and negative jumps, I separate the jumps into positive and negative jump categories. Contrary to Wang's (2015) study, the USD/JPY pair has the most positive jumps 


\section{S. Yeşilyurt - Ü. Erol 13/4 (2021) 3559-3572}

together with the EUR/GBP pair in all frequency levels. Except for EUR/GBP, USD/JPY, EUR/CHF, and EUR/TRY, I find more negative jumps than positive jumps during the observation periods. The reason for this asymmetry may be due to a decrease in the dollar and Euro indexes. The U.S. Dollar Index (USDX), indicates (in the time of study) the general initial value of the USD calculated by averaging the exchange rates between the USD and other major world currencies.

There are many anomalies in finance. Day of the week is the most meaningful one for the FX market. Monday and Wednesday have the highest jumps in a week. Monday's jumps have an accumulation effect. I can say that there is a weekend effect here. Scheduled macro-economic news is the one that mostly affects the jumps, but there is unscheduled news like speeches, which also have more effect on jumps. This study has not given more focus on unscheduled news, but it significantly affects jumps. It increases the magnitude of the jumps.

To draw attention to the jump and macroeconomic news announcement, I chose the 10 largest EUR/USD jumps and matched them to the macroeconomic news announcements. It shows that at least one macroeconomic news announcement is associated with the jumps. I can notice that the largest jumps are matched to at least one macroeconomic news announcement. When a big jump occurs in one FX market, seeing the jump in other markets is quite possible. I have focused only the scheduled news announcements, but unscheduled news exists in the markets. This unscheduled news also has significant effects on jumps.

Table. 4 shows how closely exchange rates jump match with the scheduled macroeconomic news announcement. I collected 10,850 scheduled news announcement in total. Some of them are related to the jumps, but others are not related to jumps.

Table 4 Descriptive statistics of jump and news (BNS Method)

\begin{tabular}{|c|c|c|c|c|c|c|c|c|c|c|c|}
\hline & \begin{tabular}{|c|} 
CHFJP \\
$Y$ \\
\end{tabular} & GBPCHF & \begin{tabular}{|c|} 
GBPJP \\
$Y$ \\
\end{tabular} & \begin{tabular}{|c|} 
USDC \\
HF
\end{tabular} & \begin{tabular}{|c|} 
USDJ \\
PY \\
\end{tabular} & \begin{tabular}{|c|} 
USDT \\
RY \\
\end{tabular} & \begin{tabular}{|c|} 
EURC \\
HF
\end{tabular} & \begin{tabular}{|c|} 
EURG \\
BP \\
\end{tabular} & $\begin{array}{c}\text { EURJ } \\
\text { PY }\end{array}$ & \begin{tabular}{|c|} 
EURT \\
RY
\end{tabular} & $\begin{array}{c}\text { EURU } \\
\text { SD }\end{array}$ \\
\hline $\begin{array}{l}\# \\
\text { observations }\end{array}$ & 735,264 & 735,264 & 735,264 & \begin{tabular}{|c|}
735,26 \\
4
\end{tabular} & \begin{tabular}{|c|}
735,26 \\
4 \\
\end{tabular} & \begin{tabular}{|c|}
735,26 \\
4 \\
\end{tabular} & 735,264 & \begin{tabular}{|c|}
735,26 \\
4 \\
\end{tabular} & $\begin{array}{c}735,26 \\
4 \\
\end{array}$ & 735,264 & $\begin{array}{c}735,26 \\
4\end{array}$ \\
\hline \# of days & 2555 & 2555 & 2555 & 2555 & 2555 & 2555 & 2555 & 2555 & 2555 & 2555 & 2555 \\
\hline \# news & 10850 & 10850 & 10850 & 10850 & 10850 & 10850 & 10850 & 10850 & 10850 & 10850 & 10850 \\
\hline \# news days & 2355 & 2355 & 2355 & 2355 & 2355 & 2355 & 2355 & 2355 & 2355 & 2355 & 2355 \\
\hline$P$ (news) \% & 0.922 & 0.922 & 0.922 & 0.922 & 0.922 & 0.922 & 0.922 & 0.922 & 0.922 & 0.922 & 0.922 \\
\hline \# Jumps & 1136 & 1198 & 1565 & 1155 & 1168 & 1450 & 1117 & 1381 & 1229 & 1258 & 1433 \\
\hline $\begin{array}{l}\text { \# Jumps- } \\
\text { matches } \\
\text { news }\end{array}$ & 258 & 254 & 273 & 277 & 235 & 342 & 309 & 315 & 267 & 348 & 357 \\
\hline $\begin{array}{l}P \\
(\text { jump/news) } \\
(\%)\end{array}$ & 2.38 & 2.34 & 2.52 & 2.55 & 2.17 & 3.15 & 2.85 & 2.90 & 2.46 & 3.21 & 3.29 \\
\hline \begin{tabular}{|l|} 
P \\
$($ News/Jump \\
$(\%)$ \\
$(\%)$
\end{tabular} & 22.71 & 21.20 & 17.44 & 23.98 & 20.12 & 23.59 & 27.66 & 22.81 & 21.72 & 27.66 & 24.91 \\
\hline $\begin{array}{l}\text { P } \\
(\text { jump/news) } \\
(\%)\end{array}$ & 0.035 & 0.035 & 0.037 & 0.038 & 0.032 & 0.047 & 0.042 & 0.043 & 0.036 & 0.047 & 0.049 \\
\hline
\end{tabular}

Source: Author's own calculation.

When we look at the descriptive statistics, the probability of the unconditional announcements is $0.92 \%$. It means that $0,92 \%$ intraday intervals have at least one macroeconomic announcement occurrence. The critical question is whether news announcements cause a jump? I calculate the occurrence of the jumps within the 30 minutes after the news announcement (calculated as \# of the jump match news). The EUR/USD, EUR/TRY, and USD/TRY have the most jumps corresponding to the macroeconomic news announcements, while the 
$\mathrm{GBP} / \mathrm{CHF}$ has the least number of matched-jumps, 254. P\{jumps|news $\}$ shows the probability of the jump conditional on a macroeconomic news announcement. The range of \{jumps|news\} from 2.17 to 3.29 indicates that there is no huge differences between eleven currency pairs. $P\{$ news $\mid j u m p s\}$ says how many jumps are related to the macroeconomic news announcement. It fluctuated from $17.44 \%$ to $27.66 \%$, and this result indicates that many of the existing forex jumps probably emerge from the macroeconomic news announcement. The last part, $P\{$ jumps $\mid$ news $\}$ indicates that the percentage of the jump-news match within the total observation. The highest $P\{$ jumps $\mid$ news $\}$ rate is 0,049 , and the lowest one is 0,032 . This shows that there is no big differences between the highest and lowest probabilities. When I was examining the category of the news announcements, I realized that ABD Consumer Confidence, Bloomberg Global Confidence, ABD Employment Change, Business Climate index, New Home Sales, ECB announcement Interest Rate, CPI Ex Food and Energy, Current Account Balance, Labor Costs SA, Trade Balance, FOMC Rate Decision, BOJ Basic Balance Rate, Initial Job Claims, Chamber Votes Confidence on Deficit Cuts, House Price Index, and General Government Debt and Bloomberg GDP Monthly Estimate have more potential impact on the jumps.

Table. 5 provides more details about how closely the exchange rate jumps match the scheduled macroeconomic news announcement. In total, there are 10,850 scheduled news announcements. To clarify whether news announcement causes jumps, I consider the lag effect of the announcements. It means that when the announcement occurs, the possible effect is executed after or before the news announcement.

Table 5 Largest EUR/USD Jumps matched with macroeconomic news

\begin{tabular}{|c|c|c|c|c|c|c|c|}
\hline \multicolumn{8}{|c|}{ MERGE EURUSD WITH NEWS } \\
\hline Time & Country & News & $\begin{array}{l}1 \text { Minutes } \\
\text { frequency }\end{array}$ & $\begin{array}{c}5 \text { Mins } \\
\text { Frequency }\end{array}$ & \begin{tabular}{||c||}
15 Mins \\
Frequenc \\
$y$ \\
\end{tabular} & $\begin{array}{c}30 \text { mins } \\
\text { Frequency }\end{array}$ & \begin{tabular}{|c}
60 mins \\
Frequenc \\
$y$ \\
\end{tabular} \\
\hline \begin{tabular}{|c|}
01.06 .10 \\
$10: 00$ \\
\end{tabular} & $\begin{array}{l}\text { United } \\
\text { States } \\
\end{array}$ & $\begin{array}{c}\text { ABD Consumer } \\
\text { Confidence } \\
\end{array}$ & 0.534603 & 0.5300978 & || 2.218841 & 0.3857545 & 0.854854 \\
\hline \begin{tabular}{|c|}
02.10 .10 \\
$14: 00$ \\
\end{tabular} & $\begin{array}{l}\text { United } \\
\text { States } \\
\end{array}$ & $\begin{array}{c}\text { Bloomberg Global } \\
\text { Confidence }\end{array}$ & 0.482391 & 0.8733484 & | 0.1381038 & 0.0331457 & 0.2327889 \\
\hline \begin{tabular}{|c|}
01.04 .11 \\
$14: 20$ \\
\end{tabular} & $\begin{array}{l}\text { United } \\
\text { States } \\
\end{array}$ & $\begin{array}{l}\text { ABD Employment } \\
\text { Change } \\
\end{array}$ & 1.267094 & 0.228312 & 0.26268 & 0.3487291 & 1.429528 \\
\hline \begin{tabular}{|c|}
01.07 .11 \\
$04: 00$ \\
\end{tabular} & China & Business Climate Index & 1.363586 & 0.9343289 & $\mid 1.052548$ & 1.10969 & 0.3957099 \\
\hline \begin{tabular}{|c|}
02.08 .11 \\
$10: 00$ \\
\end{tabular} & $\begin{array}{l}\text { United } \\
\text { States } \\
\end{array}$ & New Home Sales & 0.315577 & 1.140027 & $0.6688684 \|$ & 0.6887274 & 0.1378783 \\
\hline \begin{tabular}{|c|}
01.12 .11 \\
$11: 00$ \\
\end{tabular} & Eurozeone & $\begin{array}{l}\text { ECB Announcement } \\
\text { Interest Rate }\end{array}$ & 0.964051 & 0.7619185 & $\mid 0.8878731 \|$ & 0.8513959 & 2.419744 \\
\hline \begin{tabular}{|c|}
04.04 .13 \\
$08: 35$ \\
\end{tabular} & $\begin{array}{c}\text { United } \\
\text { States } \\
\end{array}$ & CPI Ex Food and Energy & 0.232815 & 3.366511 & 3.385785 & 0.969689 & 1.786926 \\
\hline \begin{tabular}{|c|}
12.07 .16 \\
$09: 45$ \\
\end{tabular} & France & Current Account Balance & 1.02768 & 0.8020738 & 1.21229 & 0.8465937 & 0.5529328 \\
\hline \begin{tabular}{|c|}
12.09 .16 \\
$09: 00$ \\
\end{tabular} & Germany & Labor Costs SA QoQ & 2.01471 & 0.3159773 & 0.8802566 & 0.3338352 & 1.588172 \\
\hline \begin{tabular}{|c|}
05.12 .16 \\
$14: 30$ \\
\end{tabular} & $\begin{array}{l}\text { United } \\
\text { States } \\
\end{array}$ & Trade Balance & 1.094689 & 3.141009 & 0.3551635 & 0.1333704 & 1.094689 \\
\hline \begin{tabular}{|c|}
$01 / 17 / 11$ \\
$14: 25$ \\
\end{tabular} & $\begin{array}{l}\text { United } \\
\text { States } \\
\end{array}$ & FOMC Rate Decision & 0.531507 & 0.9104603 & 0.3176433 & 0.806296 & 0.0327121 \\
\hline \begin{tabular}{|c|}
$01 / 29 / 16$ \\
$07: 38$ \\
\end{tabular} & Japan & BOJ Basic Balance Rate & 1.963759 & 0.4420359 & 1.69314 & 3.67733 & 0.2846371 \\
\hline \begin{tabular}{|c|}
$05 / 25 / 11$ \\
$08: 35$ \\
\end{tabular} & $\begin{array}{l}\text { United } \\
\text { States } \\
\end{array}$ & Initial Job Claims & 0.132368 & 0.7366009 & 1.361477 & 0.3367218 & 1.308521 \\
\hline
\end{tabular}


S. Yeşilyurt - Ü. Erol 13/4 (2021) 3559-3572

\begin{tabular}{|c|c|c|c|c|c|c|c|}
\hline $\mid$\begin{tabular}{c||}
$07 / 27 / 10$ \\
$16: 00$
\end{tabular} & Italy & $\begin{array}{c}\text { Chamber Votes } \\
\text { Confidence on Deficit } \\
\text { Cuts }\end{array}$ & 0.964835 & 0.2660378 & 0.6627792 & 0.2255138 & 0.3686878 \\
\hline \begin{tabular}{|c||}
$12 / 13 / 16$ \\
$11: 30$ \\
\end{tabular} & $\begin{array}{c}\text { United } \\
\text { Kingdom }\end{array}$ & House Price Index YoY & 0.116775 & 0.5893646 & 0.5316566 & 1.719844 & 0.3653325 \\
\hline $\begin{array}{c}12 / 15 / 16 \\
11: 30\end{array}$ & Italy & $\begin{array}{c}\text { General Government } \\
\text { Debt }\end{array}$ & 1.606214 & 1.655951 & $\mid 1.606214$ & 0.3488216 & 0.6064087 \\
\hline \begin{tabular}{|c||}
$20 / 01 / 15$ \\
$10: 00$
\end{tabular} & China & $\begin{array}{c}\text { Bloomberg GDP Monthly } \\
\text { Estimate YoY }\end{array}$ & 0.91323 & 1.0433784 & $\mid 1.0772075$ & 0.8009661 & 0.84122 \\
\hline
\end{tabular}

Source: Author's own calculation.

Jumps are the individual movements in currency pairs. There is also co-jump as two or three jumps occurring simultaneously among the other two or three exchange rate pairs. Co-Jumps will also be discussed in my further srudies.

\section{CONCLUSION AND FUTHER STUDIES}

The first part of the article concentrates on the conceptual framework and theory of the jumps and co-jumps. I present the quadratic variation and standard jump-diffusion and jump detection models in which the price processes are separated as continuous and jump components. I have presented the non-parametric metric of quadratic variation, realized variance, and bipower variation, which is robust to jump detection and estimating the continuous path variation. I aim to identify foreign exchange rate market jumps and investigate how macroeconomic releases are related to these discontinuities. I use 1-min high-frequency data on eleven exchange rates (CHF/JPY, EUR/CHF, EUR/JPY, EUR/TRY, EUR/USD, GBP/CHF, GBP/JPY, USD/CHF, USD/JPY, USD/TRY, and EUR/GBP) are investigated for six years from 2010 to 2016. I employ the Hausman type jump detection test proposed by Barndorff-Nielsen and Shephard (2006) this is based on the differences between realized variance and bipower variation and Aith-Sahalia and Jacord (2009) jump detection tests to detect intraday rice jumps for eleven exchange rate pairs.

Even though there is remarkable literature about jumps in financial markets, to our knowledge, there are less studies which deeply considered their reactions to macroeconomic news announcements. The jump detection measure we use was proposed by Barndorf, Nielsen, and Shephard (2006) and Ait-Sahalia-Jacod test (2009) remove any periodic patterns for robustness. More importantly, I apply the event study approach (news analysis) to catch the news effects 30 minutes after the announcement.

First, I find that jumps detection test results are quite similar between BNS and AJ tests. The detected jumps are related to economic fundamentals, but jumps are only a small proportion of the sample news data. Jump doesn't have long-term memory. The effect is temporal and disappears very quickly. Scheduled news announcements have significant effects on jumps. There are also speeches and unscheduled news, but scheduled news more influential because it is announced more frequently than speeches.

Secondly, scheduled news announcements related to employment, real activity monetary policy, current account have significant effects on jumps. ABD consumer confidence, Bloomberg global confidence, FOMC Rate Decision, ABD employment change, Business climate index, New home sales, ECB Announcement on the interest rate, Current account balance, Labor costs, Trade balance, House price index, General government debt, and GDP expectations have notable effects on jumps.

Thirdly, the null hypothesis that jumps are independent is rejected, as there are far more co-jumps than predicted by independence for all rate combinations. Some clustering of jumps and co-jumps are also detected and relate to the macroeconomic news announcements affecting the exchange rates (This effect will be discussed in my further studies).

Fourthly, Andersen et al. (2007) find that the predictability in volatility is mainly related to continuous diffusion and that jumps are not important. In contrast to the univariate case, predictability in average volatility across a group of assets can be linked to the occurrence of co-jumps. It is said that volatility rises subsequently to co-jump occurring. Another thing is that level of volatility doesn't influence the probability of co-jump occurring. However, the negative and positive jumps affect the volatility in different magnitudes. 
Lastly, I choose one emerging market currency pairs, and it is the fist, and comprehensive study includes emerging market news and exchange rate data into the analysis. The results show that emerging market countries are sensitive and affect the low level of news besides the major market movements.

This article proves that jumps are the predictors of the discontinuities in foreign exchange rate markets. It is also proven that macroeconomic fundamentals have a significant effect on jumps. There is a strong correlation between stock returns and jumps. This correlation is not the only one that signals and explains the comovements in that market. Different metrics affect co-movements. The news's exact effect can be realized in three stages - pre-event, event, and post-event time. I focussed on the event and post-event time in this article and verified that post-event time has a significant effect to match the jumps. The results of this study can be used by finance practitioners and researchers, especially for behavioral finance's cases. I find out the importance of jumps and their initial relation with the macroeconomic news announcements. Apart from this research, I can extend my study to co-jump and wavelet base new non-parametric tests by decomposing data into different time cycles and detect the arrival time of the jumps and co-jumps. I can apply these tests either in equity markets or bond markets too.

\section{REFERENCES}

Aït-Sahalia, Y., \& Jacod, J. (2009). Testing for jumps in a discretely observed process. The Annals of Statistics, 184-222.

Andersen, J. V. (2010). Detecting anchoring in financial markets. Journal of Behavioral Finance, 11(2), 129-133.

Andersen, T. G., Bollerslev, T., \& Diebold, F. X. (2007). Roughing it up: Including jump components in the measurement, modeling, and forecasting of return volatility. The review of economics and statistics, 89(4), 701-720.

Andersen, T. G., Bollerslev, T., \& Dobrev, D. (2007). No-arbitrage semi-martingale restrictions for continuoustime volatility models subject to leverage effects, jumps and iid noise: Theory and testable distributional implications. Journal of Econometrics, 138(1), 125-180.

Andersen, T. G., Dobrev, D., \& Schaumburg, E. (2012). Jump-robust volatility estimation using nearest neighbor truncation. Journal of Econometrics, 169(1), 75-93.

Andersen, T., G., Bollerslev, T.(1998). Deutsche Mark - Dollar Volatility : Intraday Activity Patterns , Macroeconomic Announcements, Journal of Finance, 53 (1), 219-265

Balduzzi, P., Elton, E. J., \& Green, T. C. (2001). Economic news and bond prices: Evidence from the US Treasury market. Journal of financial and Quantitative analysis, 36(4), 523-543.

Barndorff-Nielsen, O. E., \& Shephard, N. (2004). Power and bipower variation with stochastic volatility and jumps. Journal of financial econometrics, 2(1), 1-37.

Barndorff-Nielsen, O. E., \& Shephard, N. (2006). Econometrics of testing for jumps in financial economics using bipower variation. Journal of financial Econometrics, 4(1), 1-30.

Basseville, M., \& Nikiforov, I. V. (1993). Detection of abrupt changes: theory and application (Vol. 104). Englewood Cliffs: Prentice Hall.

Bollerslev, T., Law, T. H., \& Tauchen, G. (2008). Risk, jumps, and diversification. Journal of Econometrics, 144(1), 234-256.

Bollerslev, T., Todorov,V.,Li, Z.,S.(2013) . Jump tails, extreme dependencies, and the distribution of stock returns.Journal of Econometrics, 172, 307-324.

Cont, R., Tankov, P. (2004). Financial Modelling with Jump Processes, second printing. Chapman and Hall/CRC Press, London 
Corsi, F., Pirino, D., \& Reno, R. (2010). Threshold bipower variation and the impact of jumps on volatility forecasting. Journal of Econometrics, 159(2), 276-288.

Dewachter, H., Erdemlioğlu, D., Gnabo, Y., J. \& Lecourt, C. (2014). The Intra-Day Impact of Communication on Euro-Dollar Volatility and Jumps. Journal of International Money and Finance.

El Ouadghiri, I., \& Uctum, R. (2016). Jumps in equilibrium prices and asymmetric news in foreign exchange markets. Economic Modelling, 54, 218-234.

Jiang, J.,G.,Oomen, C.A.,R. (2008)Testing for Jumps When Asset Prices Are Observed with Noise - A "Swap Variance" Approach. Journal of Econometrics, 1444 (2), 352-370

Lahaye, J., Laurent, S., \& Neely, C. J. (2011). Jumps, cojumps and macro announcements. Journal of Applied Econometrics, 26(6), 893-921.

Lee, S. S., \& Mykland, P. A. (2008). Jumps in financial markets: A new non-parametric test and jump dynamics. The Review of Financial Studies, 21(6), 2535-2563.

Lee, S., \& Mykland, P. A. (2012). Jumps in equilibrium prices and market microstructure noise. Journal of Econometrics, 168, 396-406.

Maheu, J.,M., Mccurdy, H.,T.(2004). News Arrival, Jump Dynamics, and Volatility Components for Individual Stock Returns. The Journal of Finance. 2. 755-793

Merton, R. (1976). Option pricing when underlying stock returns are discontinuous. Journal of Financial Economics.

Palmes, C., \& Woerner, J. H. (2013). The Gumbel test for jumps in stochastic volatility models.

Qiu, P., \& Yandell, B. (1998). Local polynomial jump-detection algorithm in non-parametric regression. Technometrics, 40(2), 141-152.

Schwert, G. W. (2011). Stock volatility during the recent financial crisis. European Financial Management, 17(5), 789-805.

Shiau, J. J. (1986). Smoothing spline estimation of functions with discontinuities. Dissertation Abstracts International Part B: Science and Engineering[DISS. ABST. INT. PT. B- SCI. \& ENG.],, 46(11).

Tauchen, G., \& Zhou, H. (2011). Realized jumps on financial markets and predicting credit spreads. Journal of Econometrics, 160(1), 102-118.

Wang, Y. (1995). Jump and sharp cusp detection by wavelets. Biometrika, 82(2), 385-397.

Wong, H., Ip, W., \& Li, Y. (2001). Detection of jumps by wavelets in a heteroscedastic autoregressive model. Statistics \& probability letters, 52(4), 365-372.

Yin, Y. Q. (1988). Detection of the number, locations and magnitudes of jumps. Communications in Statistics. Stochastic Models, 4(3), 445-455.

Zhu, S. C. (1999). Stochastic jump-diffusion process for computing medial axes in Markov random fields. IEEE Transactions on Pattern Analysis and Machine Intelligence, 21(11), 1158-1169.

Zoi, P.(2017). Price and Volatility Jumps in the Stock Markets, PhD Thesis, Department of Economics Ca' Foscari University of Venice.

Zoi, P., Ferriani, F.(2017). The Dynamics of Price Jumps in the Stock Market: an Empirical Study on Europe and U.S. Paris December 2017 Finance Meeting EUROFIDAI - AFFI 